\title{
ANALISIS HARGA AIR PADA AIR PERMUKAAN UNTUK USAHATANI PADI SAWAH DI SUBAK BENGKEL, KECAMATAN KEDIRI, KABUPATEN TABANAN
}

\author{
Water Price Analysis of Surface Water for Rice Farmingin Subak Bengkel, \\ Kecamatan Kediri, Tabanan District

\section{Pande Made Ari Ananta Paramarta*)} \\ Widhianthini \\ A.A.A. Wulandira Sawitri Djelantik
}

Fakultas Pertanian, Universitas Udayana, Bali, Indonesia

Email : ariananta230@gmail.com*)

\begin{abstract}
Bengkel Subak is the widest subak in Kediri District, Tabanan Regency. Subak Bengkel has a total area of 329 hectares, which is divided into 19 Tempek, which is some kind of grouping. Bengkel Subak is located on two villages, Bengkel Village and Pangkung Tibah Village. The water acquisition is also agreed based on the water debit in each place. This study aims to determine the price of water used by farmers in Subak Bengkel paddy farming, also to know the influence of production and constraints factors experienced in rice farming. The results calculation with the use of value of marginal product (VMP) approach showed that the price of water for irrigated paddy in Subak Bengkel was Rp 413,593.85 / ha / year, around 206,796.92 / ha / planting season or around Rp 206.79 / m3, where the most influential factor is seedlings with an elasticity coefficient of 0.861 affecting production of 8.61 percent. The most common obstacle experienced by Subak Bengkel farmers is the pest in the form of crabs that damage the rice field dike. In the future, Bengkel Subak will include water discharge as an production input in rice farming for appreciation of water resources.
\end{abstract}

Keywords : Subak, Water price, Paddy

\begin{abstract}
ABSTRAK
Subak Bengkel merupakan subak terluas di Kecamatan Kediri, Kabupaten Tabanan. Subak Bengkel memiliki total luas 329 Ha yang terbagi menjadi 19 tempek. Subak Bengkel mewilayahi dua desa yaitu Desa Bengkel dan Desa Pangkung Tibah.

Penelitian ini bertujuan untuk mengetahui harga air yang dimanfaatkan petani dalam berusahatani padi sawah di Subak Bengkel yang dibarengi dengan mengetahui pengaruh faktor faktor produksi dan kendala kendala yang dialami dalam usahatani padi sawah. Hasil penelitian menunjukan bahwa perhitungan menggunakan pendekatan value of marginal product (VMP) menunjukkan harga air untuk irigasi padi sawah di Subak Bengkel adalah
\end{abstract}


sebesar $\mathrm{Rp}$ 413.593,85 /ha/tahun, sekitar 206.796,92 /ha/musim tanam atau sekitar $\mathrm{Rp}$ $206,79 / \mathrm{m}^{3}$, dimana faktor profuksi yang paling berpengaruh adalah bibit dengan koefisien elastisitas sebesar 0,861 yang mepengaruhi produksi sebesar 8,61 persen. Kendala yang dialami petani Subak Bengkel yang paling banyak dialami adalah hama berupa kepiting yang merusak pematang sawah. Subak Bengkel kedepannya harus memasukan debit air sebagai input produksi dalam usahatani padi sawah sebagai penghargaan terhadap sumber daya air.

Kata kunci : Subak, Harga air, Padi

\section{PENDAHULUAN}

\section{Latar Belakang}

Air merupakan salah satu sumberdaya alam yang sangat penting. Keberadaan air memberikan manfaat yang sangat besar bagi kelangsungan hidup di muka bumi. Setiap makhluk hidup membutuhkan air untuk memenuhi kebutuhannya. Hewan, tumbuhan, dan makhluk hidup lain termasuk manusia tidak dapat terlepas dari air (Anggraini, 2013). Provinsi Bali sebagai salah satu provinsi di Indonesia yang mengandalkan sektor pertanian sebagai sektor utama dalam pembangunan ekonomi masyarakatnya memiliki sistem irigasi bernama Subak. Menurut Windia (2015) subak adalah kelompok petani pengelola air irigasi, dalam suatu kawasan sawah tertentu, memiliki sumber air tertentu, memiliki pura, dan otonom. Air adalah suberdaya yang sangat penting bagi petani. Perda Provinsi Bali No.9 Tahun 2012 tentang subak menyatkan bahwa subak adalah organisasi tradisional di bidang tata guna air dan atau tata tanaman di tingkat usahatani pada masyarakat adat di Bali yang bersifat sosioagraris, religius, ekonomis, yang secara historis terus tumbuh dan berkembang (Sumiyati, 2017). Menurut Anwar dan Utomo, (2013, dalam fitri, 2016) metode yang dapat dipakai dalam menghitung tarif biaya jasa pengelolaan sumber daya air antara lain (1) full cost pricing (2) subsidized cost pricing (3) tarif dasar dengan mempertimbangkan perbedaan layanan (4) tarif percentage (5) marginal pricing.

Kecamatan Kediri merupakan salah satu kecamatan di Kabupaten Tabanan. Menurut BP3K Kecamatan Kediri (2017) menyatakan bahwa Kecamatan Kediri, Kabupaten Tabanan memiliki total 23 subak, dengan total luas keseluruhan 2.839 Ha. Subak Bengkel merupakan subak terluas di Kecamatan Kediri, Kabupaten Tabanan. Subak Bengkel memiliki total luas $329 \mathrm{Ha}$ yang terbagi menjadi 19 tempek. . Menurut I Made Merta Suteja salah satu tokoh di Subak Bengkel, Subak Bengkel sudah mengalami penururan debit air dan pendangkalan saluran irigasi akibat adanya imbas pariwisata dari Objek Wisata Tanah Lot dan Objek Wisata Pantai Yeh Gangga. Penurunan debit air yang terjadi di Subak Bengke saat ini sekitar 30\%. Petani Subak bengkel belum pernah mencantumkan sumber daya air sebagai biaya input dalam usahataninya, sehingga air masih dianggap barang yang free atau gratis penggunaannya oleh petani di Subak Bengkel. Sebenarnya harus memperhatikan hal tersebut agar sumber daya air permukaan pada saluran irigasi dapat terjaga kualitas dan kuantitasnya. Petani di Subak Bengkel juga masih mengalami beberapa kendala dalam pemanfaatan irigasi Subak Bengkel. 


\section{Tujuan Penelitian}

Tujuan dari penelitian ini adalah untuk mengetahui: harga air yang dimanfaatkan petani dalam berusahatani padi sawah di Subak Bengkel, Kecamatan Kediri, Kabupaten Tabanan yang dibarengi dengan mengetahui faktor faktor yang mempengaruhi padi sawah di Subak Bengkel, Kecamatan Kediri, Kabupaten Tabanan dan mengetahui kendalakendala dalam pemanfaatan air irigasi pada Subak Bengkel, Kecamatan Kediri, Kabupaten Tabanan.

\section{METODOLOGI PENELITIAN}

Lokasi dari penelitian ini adalah Subak Bengkel yang terletak di Kecamatan Kediri, Kabupaten Tabanan. Subak Bengkel mewilayahi dua desa yaitu Desa Bengkel dan Desa Pangkung Tibah. Penelitian ini dilakukan pada awal bulan Januari 2020 sampai akhir bulan Februari 2020. Data yang diambil adalah data untuk dua musim tanam pada tahun 2019. Pemilihan lokasi penelitian dilakukan secara sengaja (purposive), dengan pertimbangan 1) subak Bengkel adalah subak yang menggunakan sumber air yang bersumber dari air permukaan untuk kegiatan pertanian padi sawah, 2) Subak Bengkel mengalami penurunan debit air sekitar 30\% yang bisa mempresentasikan keadaan subak lainnya di Tabanan yang mulai mengalami penurunan ketersediaan sumber air, 3) petani pengguna air permukaan di Subak Bengkel sebagian besar menggunakan sistem tanam penggenangan air untuk budidaya padi sawah yang dilakukan secara terus menerus.

Metode yang digunakan dalam mengumpulkan data dalam penelitian antara lain library research, field research, dan wawancara dimana merupakan teknik pengumpulan data jika peneliti ingin mengetahui hal-hal dari subjek penelitian lebih mendalam seperti kualitas air, pola tanam yang dijalankan, dan awal mula penentuan biaya urunan untuk kegiatan upacara dan pembangunan subak.

\section{Metode Analisis}

Pengukuran yang digunakan dalam penelitian ini adalah dengan menggunakan metode kuantitatif. Faktor-faktor yang mempengaruhi produksi padi sawah digunakan analisis regresi dan dilanjutkan dengan harga air saluran irigasi dilakukan perhitungan nilai air berdasarkan pendekatan nilai produk marginal pada sistem pertanian khususnya padi sawah. Pendekatan yang digunakan adalah pendekatan fungsi produksi Cobb-Douglas (Gujarati, 2003, dalam Sudarma, 2015), dengan persamaan sebagai berikut:

$Y=b_{0} X_{1}^{b 1} X_{2}^{b 2} X_{3}^{b 3} X_{4}{ }^{b 4} X_{5}{ }^{b 5} X_{6}{ }^{b 6} \mu$

Dimana:

$Y \quad=$ Produksi padi $(\mathrm{kg})$

$X_{1} \quad=$ Luas tanam (hektar)

$X_{2} \quad=$ Benih $(\mathrm{kg})$

$X_{3} \quad=$ Pupuk $(\mathrm{kg})$

$X_{4} \quad=$ Obat-obatan/pestisida (lt)

X5 = Tenaga Kerja (HOK) 


$$
\begin{array}{ll}
\text { X6 } & =\text { Air } \quad(\text { Liter per detik }) \\
\text { b0 } & =\text { Konstanta } \\
\text { b1 } \ldots \text { b6 } & =\text { Koefisien elastisitas } \\
\mu \quad & \text { Kesalahan model }
\end{array}
$$

Fungsi tersebut kemudian ditransformasi menjadi bentuk logaritma natural (ln) sehingga didapatkan model persamaan linier sebagai berikut:

$\operatorname{Ln} Y=\ln b_{0}+b_{1} \ln X_{1}+b_{2} \ln X_{2}+b_{3} \ln X_{3}+b_{4} \ln X_{4}+b_{5} \ln X_{5}+b_{6} \ln X_{6}+\mu$.

Analisis regresi dilakukan menggunakan program perangkat lunak SPSS 22 maka didapatkan nilai koefisien regresi $\left(b_{i}\right)$ dari faktor produksi yang akan menunjukan besaran nilai elastisitas. Dengan asumsi petani berusaha mencapai keuntungan maksimum, maka harga air adalah sama dengan nilai produk marginal air (NPMair) atau value of marginal product $\left(\mathrm{VMP}_{\text {air }}\right)$ yang secara matematis diturunkan sebagai berikut:

$$
\begin{aligned}
& H_{A i r}=V M P_{A i r} \ldots \ldots \\
& V P_{a i r}=M P_{A i r} \times P q \\
& H_{A i r}=M P_{A i r} \times P q \ldots \\
& H_{A i r}=\varepsilon \times A P \times P q \ldots \\
& H_{A i r}=b_{6} \times A P \times P q
\end{aligned}
$$

Dimana:

$$
\begin{array}{ll}
H_{\text {Air }} & =\text { Harga air }(\mathrm{Rp} / \mathrm{hektar}) \\
M P_{\text {Air }} & =\text { Marginal produk air } \\
P q & =\text { Harga padi }(\mathrm{Rp}) \\
\varepsilon & =\text { Elastisitas } \\
b_{6} & =\text { Elastisitas permintaan air } \\
A P & =\text { Average product }
\end{array}
$$

Untuk mengetahui kendala-kendala dalam pemanfaatan air irigasi dianalisis dengan menggunakan analisis deskriptif kuantitatif. Metode pendekatan yang digunakan pada analisis deskriptif kuantitatif adalah statistik deskriptif. Menurut Sugiyono (2011), statistik deskriptif adalah statistik yang digunakan untuk menganalisis data dengan cara mendeskripsikan atau menggambarkan data yang telah terkumpul sebagaimana adanya tanpa bermaksud membuat kesimpulan yang berlaku untuk umum atau generalisasi.

\section{HASIL DAN PEMBAHASAN}

Koefesien regresi pada luas lahan bernilai 0,200, artinya bahwa apabila dilakukan penambahan input luas lahan 10 persen, maka mengakibatkan peningktan produksi padi 2 persen. Peningkatan 10 persen dari penggunaan tenaga kerja akan menyebabkan kenaikan hasil produksi padi sebanyak 0.92 persen. Peningkatan input bibit sebesar 10 persen akan menyebabkan peningkatan hasil produksi padi 8,61 persen, kenaikan penggunaan input pupuk 10 persen mengakibatkan kenaikan hasil produksi padi sawah sebanyak 2,16 persen, peningkatan input obat-obatan 10 persen dapat menyebabkan penurunan hasil produksi padi sebesar 2,73 persen dan apabila pengunaan air 
bahkan diserap untuk memenuhi kebutuhan rumah tangga. Rata rata debit air yang kemudian dapat di terima oleh petani $11,24 \mathrm{l} / \mathrm{dt} /$ tenah.

Hasil perhitungan menggunakan pendekatan value of marginal product (VMP) menunjukkan harga air untuk irigasi padi sawah di Subak Bengkel adalah sebesar Rp 413.593,85 /ha/tahun, sekitar 206.796,92 /ha/musim tanam atau sekitar Rp 206,79/ $\mathrm{m}^{3}$. Hasil penelitian ini lebih kecil jika dibandikan dengan penelitian yang dilakukan Sudarma (2015) di DAS Ayung yaitu Rp 314.000,00 /ha/musim tanam. Hasil penelitian ini juga lebih kecil dibandingkan dengan Mahardika (2018) di DI Sangsit yaitu 379.932,43. Harga air yang lebih kecil ini disebabkan karena nilai marginal produk atas air di daerah penelitian lebih besar dibandingkan dengan hasil nilai produksi penelitian di DAS Ayung dan DI Sangsit.

Pemanfaatan saluran irigasi tentunya para petani akan menghadapi berbagai kendala. Kendalakendala yang terjadi dalam pemanfaatan air irigasi di Subak Bengkel antara lain 1) Kekurangan air di beberapa tempek, 2)penggunaan air bergilir, 3) kebanjiran dimusim hujan, 4) Penurunan debit air dimusim kemarau, 5) Hama Kepiting yang merusak pamatang sawah. Tabel kendala dapat dilihat pada Tabel 2 .

Tabel 2. Kendala Pemanfaatan Air Irigasi

\begin{tabular}{|c|c|c|c|}
\hline No & Kendala pemanfaatan air irigasi & Jumlah Responden & Persentase \\
\hline 1 & Kekurangan air di beberapa tempek & 10 & $20 \%$ \\
\hline 2 & Penggunaan air bergilir & 6 & $12 \%$ \\
\hline 3 & Kebanjiran dimusim hujan & 4 & $8 \%$ \\
\hline 4 & Penurunan debit air dimusim kemarau & 5 & $10 \%$ \\
\hline 5 & $\begin{array}{l}\text { Hama Kepiting yang merusak } \\
\text { pamatang sawah }\end{array}$ & 25 & $50 \%$ \\
\hline \multicolumn{2}{|r|}{ Total } & 50 & $100 \%$ \\
\hline
\end{tabular}

\section{SIMPULAN DAN SARAN}

\section{Simpulan}

Simpulan dari penelitian ini antara lain :

1. Kontribusi bibit menyebabkan peningkatan paling tinggi produksi padi sawah di Subak Bengkel dibandingkan input-input lainnya.

2. Harga air yang pantas di bayarkan oleh petani dalam berusahatani padi sawah di Subak Bengkel untuk mencapai kenutungan maksimum adalah sebesar $\mathrm{Rp}$ 413.593,85 /ha/tahun, sekitar 206.796,92 /ha/musim tanam atau sekitar Rp 206,79 /m3.

3. Kendala-kendala yang terjadi dalam pemanfaatn air irigasi di subak bengekel seperti kekurangan air di beberapa tempek, penggunaan air bergilir, kebanjiran dimusim hujan, penurunan debit air dimusim kemarau, dan hama kepiting yang merusak pamatang sawah 


\section{Saran}

Subak Bengkel sebaiknya memasukkan debit air sebagai input produksi yang penting dalam usaha tani padi sawah. Subak Bengkel kedepannya mempertimbangkan perhitungan harga air yang dimanfaatkan petani atau stakeholder lainnya, agar air dapat diberikan penghargaan yang pantas, selain itu petani Subak Bengkel mau merawat saluran irigasinya, agar air dapat terus mengalir dengan baik untuk usahataninya. Terkait dengan kelembagaan, Subak Bengkel bersama pemerintah dapat bekerjasama untuk meningkatkan infrastuktur saluran irigasi, agar pemanfaatan air irigasi lebih maksimal dan efisien.

\section{DAFTAR PUSTAKA}

Antara, Made. 2010. Bahan Ajar Metodologi Penelitian Sosial Ekonomi. Program Studi Agribisnis Fakultas Pertanian Universitas Udayana. Denpasar.

Anggraini, Iin. 2015. Departemen Estimasi Nilai Ekonomi Perlindungan Sumber Mata Air (Kasus Desa Cihideung Udik, Kecamatan Ciampea, Kabupaten Bogor, Jawa Barat). Institut Pertanian Bogor.

Cohen, L., Manion, L and Morrison, K. 2007. Research Methods In Education. Routledge Publishers (part of the Taylor \& Francis group), Oxford, UK.

Fitri, F Rahmi. 2016. Analisa Penetapan Biaya Jasa Pengelolaan Sumber Daya Air Irigasi Di Daerah Irigasi Riam Kanan . Institut Teknologi Sepuluh November.

BP3K Kecamatan Kediri. 2017. Kondisi Wilayah Kecamatan Kediri, Kabupaten Tabanan.

Mahardikara KY. 2018. Analisis Penetapan Harga Air di Subak Dangin Yeh Desa Sawan Emas Kecamatan Sawan, Kabupaten Buleleng. Jurnal Agribisnis dan Agarowisata. Vol 8 (2): $125-134$.

Windia, Wayan, Dkk. 2015. Aspek Ritual pada Sistem Irigasi Subak sebagai Warisan Budaya Dunia. Jurnal Kajian Bali. 5(1).

Sumiyati, Dkk. 2017. Operasional dan Pemeliharaan Jaringan Irigasi Subak di Kabupaten Tabanan . Jurnal Kajian Bali. 7(1).

Sudarma, I Made. 2015. Harga Air Untuk Irigasi Padi Sawah di Kabupaten Badung. Jurnal Bumi Lestari, 1 (15): 1-9.

Sugiyono. 2011. Metode Penelitian Kuantitatif, Kualitatif dan R\&D. Bandung: Afabeta. 
